\title{
Educação Infantil: sentidos construídos por Tutoras Virtuais sobre o lugar do Estágio na formação de professores a distância
}

\author{
Aline Sommerhalder* \\ Luana Zanotto** \\ Camila Marques dos Santos***
}

\begin{abstract}
Resumo
O artigo apresenta parte de um estudo concluído em um curso de Pedagogia, na modalidade de educação a distância de uma universidade pública federal, que aderiu ao Sistema Universidade Aberta do Brasil. Teve como questões de pesquisa: Que sentidos tutores virtuais em exercício apresentam sobre o Estágio Curricular Supervisionado em Educação Infantil, no processo de formação inicial de professores? Para tutores virtuais, que lugar esse Estágio ocupa no processo de formação inicial para a docência na educação infantil? A investigação anunciou as possibilidades formativas do Estágio e alguns de seus limites na formação inicial de professores. Foram sujeitos sete tutoras virtuais em exercício na disciplina "Estágio Supervisionado em Educação Infantil". De abordagem qualitativa, o estudo fez uso de questionário e da análise de conteúdo. O Estágio apresentou-se como momento formativo no processo de reflexão de aprendizagens relativas à docência na educação infantil e ocupou um lugar de interlocução teoria e prática. Entre os limites, tem-se o tempo para convivência em estágio e as interações de alunos-professores no Moodle.

Palavras-chave: Estágio curricular supervisionado; Tutoria virtual; Formação de professores de educação infantil; Educação à distância.
\end{abstract}

\section{Supervised Internship in Early Childhood Education: meanings constructed by Virtual tutors about of internship in distance teacher education}

\begin{abstract}
This article presents part of a study undertook in an undergraduate course in pedagogy, in the modality of distance education of a public university, which adhered the Sistema Universidade Aberta do Brasil. The research questions were: Which meanings virtual tutors in duty present about the Supervised Stage in Early Childhood Education in the initial education process of teachers? For virtual tutors, which place does this stage take in the initial education process of teachers in early childhood education? The research has announced the formation possibilities of the stage and some of its limits in initial teacher education. Seven virtual tutors were participants in duty in "Estágio Supervisionado em Educação Infantil" discipline. Of qualitative approach, the study used a questionnaire and content analysis. The supervised intership presented as a formative moment in the learning process of reflection related to the teaching in early childhood education and has occupied a place of interlocution of theory and practice. Among the limits, we have the time to the acquaintanceship in the intership and interactions of studentsteachers in Moodle.

Keywords: Curricular supervised intership; Virtual mentoring; Teacher education for early childhood education; Distance education.
\end{abstract}

\section{Introdução}

$\mathrm{O}$ artigo em questão resulta de um estudo concluído e realizado em um curso de nível superior (graduação) de Licenciatura em Pedagogia na modalidade educação a distância do Sistema Universidade Aberta do Brasil ${ }^{1}$.

Traz considerações sobre os sentidos que tutores virtuais ${ }^{2}$ possuem do lugar que o Estágio Curricular Supervisionado em Educação Infantil ocupa na formação inicial de professores de

\footnotetext{
*Endereço eletrônico: alinesommer@ufscar.br

***Endereço eletrônico: luanazanotto@yahoo.com.br

*** Endereço eletrônico: msantos.camila@gmail.com
}

educação básica. Para a compreensão de sentidos, aproxima-se das ideias de Vygotsky (2004, 2007). Para o autor, os sentidos dizem respeito às construções singulares produzidas pelos sujeitos (mediadas por interações que se dão no meio social, em contínuo processo de internalização e exteriorização) que propiciam a apropriação de significados historicamente existentes.

A colaboração neste estudo de tutores virtuais em exercício, em uma disciplina de caráter obrigatório em um curso de Licenciatura em 
Pedagogia, anunciam as possibilidades formativas e limitações de um Estágio Supervisionado na formação inicial de professores.

Uma equipe de trabalho que atua na perspectiva da colaboração, composta por um docente e tutores virtuais é responsável pelo desenvolvimento de uma disciplina obrigatória chamada "Estágio Supervisionado em Educação Infantil". Compõe ainda a equipe de trabalho, como apoio as disciplinas de Estágios, profissionais de audiovisual (que orientam na elaboração e desenvolvimento de webconferências e vídeoaulas), profissionais de design instrucional (que respondem pela criação do ambiente virtual Moodle $e^{3}$, uma secretaria e coordenação geral de estágios, que respondem pelas articulações entre Universidade, polos de apoio presencial e escolas que são campos de estágio, tutores presenciais de estágio (que atuam em cada polo de apoio presencial realizam as articulações nos polos entre os alunos-professores e as escolas campos de estágio) e professores das escolas públicas que recebem os alunos estagiários. Importante destacar que os professores das escolas públicas realizam concomitantemente à oferta da disciplina de Estágio um curso de extensão em uma perspectiva de formação continuada e que intenciona orientá-los para o recebimento dos alunos estagiários e acompanhá-los neste processo de supervisão dos estagiários.

A disciplina de Estágio Supervisionado em Educação Infantil compõe o quinto semestre de um total de oito da matriz curricular de um curso de Licenciatura em Pedagogia de uma universidade pública federal que aderiu ao Sistema Universidade Aberta do Brasil. Foi desenvolvida, assim como as demais disciplinas do curso, em uma sala virtual Moodle e estruturada com 130 horas de duração, em forma de créditos obrigatórios curriculares. Das 130 horas, destinou-se 30 horas para atividades teóricopráticas, concretizadas por meio de estudos de literaturas, entre essas: Edwards et al, 2010; Brasil, 2009; Brasil, 2010; Ostetto, 2010; Gomes, 2011; Pimenta e Lima, 2011; orientações e atividades virtuais relativas às experiências do estágio curricular de docência na educação infantil e 100 horas de inserção em campo de estágio.

Entre as várias atividades online realizadas nesta disciplina, os alunos estagiários planejaram, desenvolveram e avaliaram um projeto de intervenção pedagógica em uma realidade de sala de educação infantil e produziram diários reflexivos de estágio. As inserções ${ }^{4}$ em campo de Estágio, compondo as demais 100 horas da disciplina ocorreram como participação ${ }^{5}$ em uma sala de aula de uma instituição pública de educação infantil e possibilitaram que os alunos estagiários acompanhassem ativamente a vida da escola e de uma sala de aula, na perspectiva da docência e analisassem, a partir de uma postura reflexiva e crítica, as experiências e cotidianos vividos, à luz de literaturas científicas.

Pimenta e Lima (2006) esclarecem que o Estágio Curricular precisa ser compreendido como atividade de relação teoria e prática, assim como atividade de pesquisa. No entanto, ainda há compreensões e propostas de estágio que dicotomizam essa relação teoria e prática e enfatizam ora a teoria ora a prática.

Para a superação de um paradigma cindido dessa relação teoria e prática, é preciso analisar o modo como os currículos de formação de professores vêm sendo arquitetados (PIMENTA; LIMA, 2006). As autoras sugerem que os currículos deixem de ser um agrupamento de disciplinas descontextualizadas da realidade que a originou. Contudo, mesmo com esse movimento de discussão da necessária relação teoria e prática nos Estágios Curriculares Supervisionados, percebe-se ainda muitos desafios, como aqueles destacados na pesquisa de Felício e Oliveira (2008, p. 228) que identificaram:

\section{[...] a dificuldade que ainda encontramos para estabelecer o pleno diálogo entre as disciplinas do curso, em função dessa formação prática; a realidade de muitos alunos que não encontram em sua rotina um espaço de tempo adequado para a realização do estágio; $e$, em algumas escolas [...] a dificuldade de estabelecer uma relação de companheirismo entre $o$ professor-estudante $e$ o professor- profissional.}

Os desafios partem de ambos os lados, tanto da universidade quanto das escolas, mas na superação deles, os futuros professores têm condições, entre muitos aspectos, de reconhecer-se como sujeitos autores de sua formação e de compreender a sala de aula como um espaço de práxis, de transformação da realidade, por meio da ação docente. Nesse sentido, Perini (2006) assim como Pimenta e Lima (2006, p. 40) concordam sobre a compreensão do Estágio na formação de professores como uma: "atividade teórica de conhecimento, fundamentação, diálogo e intervenção na realidade, esse sim objeto da práxis". 
Perini (2006) também retrata a complexidade que envolve a atividade de formação de professores, sendo ela uma tarefa ampla que envolve dimensões políticas, econômicas e técnicas. Para Felício e Oliveira (2008), a atividade de estágio deve ser encarada dentro dos pressupostos de emancipação de Paulo Freire, ou seja, valorizando os processos de desenvolvimento pessoal e cognitivo das pessoas envolvidas na relação de ensino e de aprendizagem. Além disso, considera-se a necessidade de formar um profissional reflexivo e crítico, que exercite a prática investigativa, objetivando a compreensão da realidade e a intervenção do professor, em vista do desenvolvimento e da aprendizagem das crianças.

Essa compreensão também fica evidenciada na produção de Tardif (2008). Ao falar sobre concepções e práticas para formação de professores, o autor considera:

(que) [...] os professores devem reconhecer que possuem conhecimentos e devem exercer $o$ direito de expor esse saber para formação de futuros professores; as disciplinas devem deixar de serem feitas por profissionais distantes da prática pedagógica e passar a ser pensadas na relação com o cotidiano do professor; alterar a formação fragmentada em disciplinas declarativas e distantes da vivência em sala de aula para uma formação lógica, por meio de um enfoque reflexivo, levando em conta os condicionantes reais do trabalho docente e as estratégias utilizadas para eliminar esses condicionantes na ação (TARDIF, 2008, p. 242).

Pensar os Estágios Curriculares Supervisionados nessa compreensão de formação de professores, em uma nova forma de condução dos processos de formação, como na educação à distância, engloba incluir nesse processo a função do tutor virtual e considerar a docência como um trabalho coletivo, desenvolvida por todos. Para tanto, é fundamental compreender a atividade do tutor virtual como um trabalho docente. Felício e Oliveira (2008) relatam que o docente é um importante elo entre os conhecimentos historicamente construídos e os alunos, quando há prevalência da reflexão nesse processo de formação de professores.

No documento político Referenciais de Qualidade para a Educação Superior a Distância (BRASIL, 2007) indica-se que, para haver cursos de qualidade na modalidade a distância, é preciso uma equipe multidisciplinar dividida em três categorias: docentes, tutores e técnicos-administrativos em constante qualificação. Esse mesmo documento compreende o tutor como um sujeito que participa da prática pedagógica e aponta ainda a especificidade da atuação desse profissional na equipe, como alguém que desempenha ações pedagógicas diretas com os estudantes e fortaleça o diálogo com os demais membros da equipe de trabalho, como alguém que:

\section{[...] Atua a partir da instituição mediando o} processo pedagógico junto a estudantes geograficamente distantes [...] a atribuição deste profissional é o esclarecimento de dúvidas através de fóruns de discussão pela Internet, pelo telefone, participação em videoconferências, entre outros, de acordo com o projeto pedagógico de curso. $O$ tutor a distância tem também a responsabilidade de promover espaços de construção coletiva de conhecimento, selecionar material de apoio e sustentação teórica aos conteúdos e, frequentemente, faz parte de suas atribuições participar dos processos avaliativos de ensino-aprendizagem, junto com os docentes (BRASIL, 2007, p. 21).

Em estudos que envolvem a função do tutor virtual não é possível definir uma única compreensão de tutoria, pois ela é concebida ainda em decorrência do projeto pedagógico de curso e da proposta de educação a distância da Instituição de Ensino Superior. Contudo, percebe-se o consenso da necessidade desse profissional ser um facilitador e incentivador da interatividade e da aquisição da autonomia intelectual pelo estudante, além de colaborador no processo de ensino e de aprendizagem, atuando em parceria colaborativa com o docente da disciplina.

Souza et al. (2011), ao estudar o papel do tutor em cursos a distância dentro dos critérios de relações interpessoais, interatividade e autonomia do aluno, perceberam que existem desafios para promoção da autonomia do aluno, em função dos aspectos de motivação e, nesse sentido, o tutor virtual deve privilegiar a interatividade usando as experiências dos alunos como forma de integrar o grupo e usar do feedback como forma de "contribui para que eles próprios se sintam capazes para corrigir e aprimorar suas ações de estudo" (SOUZA et al, 2011, p. 11).

Já Grossi, Costa e Moreira (2013), ao investigarem a função de tutor em instituições públicas e particulares de ensino superior, 
identificaram que em ambas as instituições são executadas as mesmas atividades, concluindo que cabe ao tutor virtual "estar atento às necessidades do aluno, atuando como mediador entre estes e os professores, portanto, facilitando a relação interativa do processo ensino e aprendizagem" (GROSSI; COSTA; MOREIRA, 2013, p. 672).

Em processos de tutoria virtual em disciplinas de Estágios Curriculares Supervisionados, as autoras Dal-Forno, Cardoso e Rinaldi (2013) acordam com os Referenciais de Qualidade para a Educação Superior a Distância (BRASIL, 2007) ao declararem que o papel do tutor virtual, na experiência de planejamento e de desenvolvimento de uma disciplina de estágio supervisionado é de ser um facilitador do processo de interação com os aspectos que envolvem a aprendizagem dos estudantes, seja na execução das atividades, melhorias dos processos ou como encorajador e incentivador de superações de desafios que os alunos percorrem durante a realização do estágio supervisionado.

Como contribuição na ampliação das discussões que envolvem o trabalho docente de tutores virtuais, a investigação desenvolvida teve como questão de pesquisa: que sentidos tutores virtuais em exercício apresentam sobre o Estágio Curricular Supervisionado em Educação Infantil, no processo de formação inicial de professores? Para tutores virtuais, que lugar esse Estágio ocupa no processo de formação inicial para a docência na educação infantil?

O objetivo do estudo foi identificar e compreender sentidos que tutores virtuais constroem sobre o Estágio Curricular Supervisionado em Educação Infantil, na formação inicial de professores.

O estudo desenvolvido colabora com outras pesquisas produzidas sobre as possibilidades formativas dos Estágios Curriculares Supervisionados em programas de formação inicial de professores, especialmente na modalidade de educação a distância. Também contribui na divulgação de saberes profissionais construídos por tutores virtuais em suas práticas docentes, considerando estes profissionais como protagonistas de práticas pedagógicas. Ressalta-se a necessidade de dar visibilidade a esses profissionais que exercem um trabalho docente e que, muitas vezes, não são devidamente reconhecidos e valorizados em seus fazeres pedagógicos.

\section{Procedimentos Metodológicos}

$\mathrm{O}$ estudo desenvolvido teve fundamento na abordagem qualitativa de pesquisa com delineamento descritivo-explicativo (BOGDAN; BIKLEN, 1994; BARDIN, 2009). Participaram como sujeitos da pesquisa sete (7) tutoras virtuais em exercício na disciplina "Estágio Supervisionado em Educação Infantil" (ofertada em 2013), pertencente ao curso de Licenciatura em Pedagogia na modalidade a distância de uma universidade pública federal. O grupo de tutoras possuía entre 23 e 36 anos de idade, todas graduadas em Pedagogia, sendo três delas com mestrado acadêmico concluído, uma encontrava-se estudando o curso de doutorado e outra realizando o mestrado acadêmico. Todas estavam engajadas na área de conhecimento compatível com o curso, com diversas experiências de trabalho e pesquisa relacionadas com o campo da educação infantil e possuíam, no mínimo, um ano de exercício de docência na Educação Infantil. Algumas destas participantes possuíam também experiência de docência nos anos iniciais do Ensino Fundamental.

Foi utilizado um questionário estruturado com oito (8) questões 'abertas', dissertativas, elaboradas em forma de roteiro e aplicadas ao término da disciplina. A pergunta 'aberta', na opinião de Negrine (1998), é interessante como instrumento de coleta de dados quando o objetivo da pesquisa é obter informações mais profundas e também quando o pesquisador não possui ideia de qual será a resposta dos sujeitos da pesquisa. O roteiro de questões abordou formação, atuação e idade; tempo de experiência em tutoria, possibilidades do Estágio Supervisionado (desenvolvido por meio de uma disciplina) para a formação dos alunos-professores e especificidades e dificuldades no trabalho em tutoria, quando em atuação em Estágio. Para o presente texto, apresenta-se parte dos resultados encontrados.

A análise dos resultados foi realizada na perspectiva qualitativa e sustentou-se nos referenciais de Minayo (1998), os quais possibilitaram revelar conteúdos presentes nos dados coletados, no exercício de analisá-los à luz da literatura científica escolhida. Os dados foram organizados em duas diretrizes de análise, construídas a partir da leitura densa das respostas das participantes do estudo e das aproximações encontradas nesses achados de pesquisa:1) Possibilidades formativas do Estágio Curricular e 2) Limites Formativos da Disciplina Estágio Curricular.

Foram respeitados todos os preceitos éticos de pesquisa no que se refere ao consentimento de participação, ao anonimato das participantes, por 
meio de nomes fictícios e à confidencialidade dos dados.

\section{Apresentação e análise dos resultados}

$\mathrm{Na}$ diretriz de análise: Possibilidades formativas do Estágio Curricular, de modo geral, as tutoras virtuais se perceberam como protagonistas nas práticas pedagógicas que ocorreram a distância, interagindo de forma direta com alunos-professores e docente da disciplina, mediando o processo de ensino e de aprendizagem e auxiliando os alunosprofessores em suas possíveis dúvidas. Compreendese que essas tutoras se veem como parte integrante $\mathrm{e}$ essencial da docência que se desenvolve na modalidade de educação a distância.

O Estágio Curricular Supervisionado, ofertado por meio de uma disciplina de componente curricular obrigatório do curso, foi apontado pelas tutoras virtuais como oportunidade, para alunosprofessores em formação, de aquisição de múltiplas aprendizagens profissionais, em especial no que tange conhecer e analisar uma prática docente contextualizada na educação infantil, considerando as especificidades desse trabalho pedagógico, refletindo sobre um cotidiano escolar a partir dos estudos teóricos realizados. Destaca a tutora virtual Lucia:

\begin{abstract}
Além das aprendizagens e desenvolvimento de cada estudante, essa disciplina possibilita o contato diário dentro do cotidiano escolar, de modo que o aluno entra e tem a oportunidade de conhecer as particularidades e singularidades $d a$ Educação Infantil e, assim também observar e refletir a docência, realizando interlocução entre teoria estudada e prática encontrada (Lucia).
\end{abstract}

Ostetto (2008) destaca que a formação do professor envolve muito mais que uma racionalidade teórico/técnica marcada por procedimentos e conceitos metodológicos. Inclui práticas pedagógicas, mas também " [...] as histórias de vida, crenças, valores, afetividade, enfim, a subjetividade de todos os sujeitos implicados" (p. 128). Em diálogo com essa ideia, argumenta a tutora virtual Vivian sobre esse estágio curricular supervisionado em um curso de formação inicial de professores:

$$
\begin{aligned}
& \text { O estágio possibilita ao estudante a inserção } \\
& \text { na escola de educaçâo infantil, }
\end{aligned}
$$

proporcionando-lhe a reflexão sobre si e das situações observadas, a partir da teoria estudada na disciplina e no curso. Por meio do estágio o aluno pode observar por um determinado período uma sala de educação infantil e refletir sobre essas situações vivenciadas pensando sobre elas e como agiria nessa realidade, considerando ainda a sua história de vida [...] (Vivian).

O Estágio Curricular Supervisionado, como uma possibilidade formativa no contexto de cursos de licenciatura, possibilita aprendizagens que ultrapassam a ideia de domínio de ferramentas metodológicas para aplicar nos cotidianos pedagógicos. Trata-se de um momento formativo que possibilita ainda reflexões e convoca a ajustar a lente de olhar (reaprendendo a olhar) para enxergar-se ainda como futuro professor, possibilitando espaços para novos sentidos sobre suas visões de mundo, crenças, ideias e concepções que afetam o modo como compreende a docência com crianças pequenas. Implica assim, em um olhar sobre os aspectos interiores da personalidade desse futuro professor (OSTETTO, 2008).

Pimenta e Lima (2011) apontam que nos Estágios é preciso que os alunos em formação para a docência possam se aproximar da realidade para se apropriar dela, para analisá-la e questioná-la criticamente, à luz das teorias.

As tutoras destacaram que a disciplina de Estágio Supervisionado em Educação Infantil concretizou um processo formativo para alunosprofessores de educação infantil. Duas tutoras ressaltaram que a disciplina não consistiu em formular respostas prontas para a solução de problemas encontrados no cotidiano das práticas docentes em salas de educação infantil, mas teve por intenção ensinar os alunos a conhecer e problematizar uma docência contextualizada e buscar compreender uma dada realidade, apoiandose nas teorias estudadas.

Trata-se de apontar caminhos possíveis para serem seguidos no que se refere à docência na educação infantil, mas não de modo instrumental e técnico e sim a partir do conhecimento e reflexão teorizada sobre um contexto em que essa docência é vivida. Destaca-se a percepção da tutora Lia: “[...] além deste contato com a instituição de Educação Infantil e as relações e contradições existentes nela, o estudante é estimulado a articular as vivências de estágio com as teorias". Regina também aponta que: "a disciplina proporciona ao estudante observar, 
vivenciar e refletir sobre a prática docente na educação infantil à luz das teorias estudadas na disciplina e ao longo do curso e, também de acordo com contexto em que se estâ". Para estas duas tutoras, essa disciplina de Estágio Supervisionado é percebida como sendo diferenciada e colaborativa na formação inicial de professores, justamente pela oportunidade formativa de reflexão e, para isso, interlocução entre teorias estudadas e práticas pedagógicas concretas, estas últimas conhecidas por meio do estágio curricular na educação infantil.

Para essas tutoras, o Estágio Supervisionado em Educação Infantil não teve por intenção levar o estudante a observar os professores em exercício, para futuramente imitar essas práticas encontradas. Suas percepções foram ao encontro do proposto por Pimenta e Lima (2006, p. 8), para os quais o Estágio Supervisionado“"...] consiste na realização de uma análise crítica fundamentada teoricamente e legitimada na realidade social em que o ensino se processa".

Considerando essas autoras, o Estágio é compreendido como oportunidade de uma aprendizagem teorizada e não apenas de origem prática, sendo uma possibilidade para múltiplas aprendizagens como, por exemplo, sobre ser professor na educação infantil na sociedade contemporânea e como se constrói e vive essa docência com bebês e crianças pequenas.

A tutora virtual Paula enfatizou especialmente algumas oportunidades formativas ofertadas pela disciplina de Estágio:

\section{[...] a disciplina possibilita ao estudante do curso de Pedagogia um contato direto com as instituições de Educação Infantil para conhecer e analisar as relações existentes nela, como o processo de ensino- aprendizagem, relação professor-crianças $e$ criança-criança, cuidar e educar, entre outros (Paula).}

Essa consideração expressa a oportunidade para o aluno-professor conhecer um cotidiano docente, os condicionantes que afetam esses fazeres pedagógicos e as múltiplas relações que se desenvolvem nesse saber fazer, incluindo a compreensão sobre a própria função da educação infantil, ou seja, educar e cuidar de forma indissociada.

Outro aspecto de destaque foi o considerável potencial formativo que as tutoras atribuíram aos fóruns virtuais que ocorreram durante a disciplina, no ambiente Moodle. Esta estratégia pedagógica é, segundo Coll e Monereo (2010), uma das mais utilizadas porque possibilita uma discussão gerada a partir de um tópico inicial que os participantes discutem sobre um determinado tema, tendo como referência de estudo um texto, um vídeo, uma animação, uma situação de ensino ou um conjunto de materiais disponibilizados pelo professor. Destacam os autores que este tipo de fórum virtual pode ser utilizado no decorrer das unidades de estudo para debates de temas específicos relativos ao programa da disciplina.

A tutora virtual Paula apontou a relevância dos fóruns virtuais que ocorreram na disciplina de Estágio: "[...] as mensagens que compõe as discussões acontecidas nesses espaços subsidiam teoricamente e respaldam o aluno quando este entra e está em campo do estágio" (Paula).

Destaca-se a importância de ambientes virtuais de aprendizagem, como o Moodle e suas diversas ferramentas em cursos de formação de professores que ocorrem na modalidade a distância. Esses ambientes interativos de aprendizagem são considerados como recursos positivos para potencializar a autoria coletiva de saberes, "facilitam a construção de propostas de produção colaborativa" (BURNISKE, 2002, p. 12). Como indicou a tutora Paula, "essa ferramenta possibilita a construção e partilha de conhecimentos que servem de interlocução no processo de conhecer uma realidade de docência e prática pedagógica na educação infantil".

Também foi destaque como colaboração na formação inicial de professores para a educação infantil, a realização no Estágio de um encontro presencial em forma de um evento denominado 'Fórum de Socialização de Estágio', que ocorreu ao final da disciplina. Esse encontro se realizou presencialmente, em cada polo de apoio presencial de oferta do curso e envolveu, além dos alunosprofessores, também a equipe da disciplina (docente e tutoras virtuais) e tutores presenciais específicos de estágio que atuam nos polos. O objetivo do encontro foi compartilhar e refletir criticamente, por meio de apresentações de experiências, dos resultados do desenvolvimento dos projetos de intervenção pedagógica e conversas sistematizadas, as aprendizagens adquiridas no estágio realizado e contou ainda com a presença de professoras das escolas públicas de educação infantil que receberam os alunos estagiários.

\section{O diálogo constante com os alunos e a troca}


de conhecimentos/saberes sobre o universo da Educação Infantil [...] trata-se de um momento único onde nos encontramos $e$ estabelecemos uma conversa muito produtiva referente às experiências de Estágio (Bete).

O fórum de socialização é outro momento interessante. Ter a oportunidade de ouvir os relatos dos estudantes me deixa, muitas vezes, emocionada. É o momento no qual eles retomam todas as vivências e teorizam suas práticas para apresentá-las (Lucia).

Na diretriz de análise: Limites Formativos da Disciplina de Estágio Curricular, o planejamento do tempo para desenvolvimento da disciplina e realização de estágio foi apresentado como um aspecto que pode ser um limitador formativo desse processo de conhecer e analisar um cotidiano de docência na educação infantil. As tutoras virtuais Carla e Lucia apontaram:

[...] um dos aspectos que merece maior atenção nessa disciplina centra-se na quantidade de horas de estágio, os estudantes enfatizaram muitas dificuldades em realizar 100 horas práticas em poucos meses (Carla).

[...] o tempo. Acho que para uma disciplina de Estágio, é necessário ampliar um pouco mais o tempo para as inserções na Unidade Escolar e realização das atividades no Ambiente Virtual de Aprendizagem (Moodle). [...]. Acredito que a disciplina precisa acontecer em um tempo de calendário letivo um pouco mais prolongado (Lucia).

Os estágios curriculares precisam apresentar aos alunos-professores condições para que eles possam identificar e transgredir um olhar simplista dos problemas de ensino e de aprendizagem, possibilitando o acompanhamento das vivências de um cotidiano escolar e construírem uma reflexão crítica do trabalho docente desenvolvido neste contexto profissional. Nesse sentido, o tempo de inserção e convivência na escola e em uma sala de aula pode se constituir em limitador ou potencializador dessas condições, particularmente quando esse se realiza de forma intensa ou processual ao longo de um tempo cronológico. Os resultados deste estudo mostram-se também colaborativos nas discussões que perpassam o tempo de desenvolvimento de disciplinas de natureza teóricopráticas, como os Estágios Curriculares, em cursos de licenciatura.

Outro aspecto que se apresentou, segundo uma tutora, como um limite formativo, da disciplina de Estágio Supervisionado para a formação inicial de professores, diz respeito ao engajamento dos alunosprofessores em compartilhar, em uma ferramenta Moodle, suas atividades, impressões e reflexões de destaque no contexto da sala de educação infantil.

Notei que uma das ferramentas de ensinoaprendizagem da disciplina, o Fórum Trocando Experiências de Estágio não foi utilizada com muita ênfase pelos alunos, mesmo depois de constantes estímulos da professora e das tutoras. $O$ motivo deste pequeno uso pode ser devido à quantidade de atividades discentes em várias disciplinas ou a não compreensão da importância dessa ferramenta para compartilhar conhecimentos (Regina).

Cabe dizer que este aspecto foi minimizado, ao longo da oferta da disciplina, quando os alunosprofessores iniciaram suas produções de diários reflexivos de estágio, em que puderam descrever, refletir criticamente e socializar no ambiente de aprendizagem Moodle suas experiências vividas em campo de estágio. Com isso, essas narrativas se constituíram em ferramentas pedagógicas privilegiadas que possibilitaram às tutoras virtuais, entre outros elementos, o acompanhamento do processo de aprendizagem que ocorria em campo de estágio e internamente na disciplina.

Também foi destaque, na perspectiva destas tutoras virtuais, o momento de compartilhar as experiências vividas nesse estágio no 'Fórum de Socialização dos Estágios', já anunciado nesse artigo como uma bem-sucedida ação formativa, ao invés de um Fórum virtual no ambiente Moodle, considerando que este último apresentou limitações quando pensado como contribuição para o processo formativo destes alunos-professores. Esse resultado é ainda importante no processo de avaliação da disciplina, buscando identificar e compreender motivos pelos quais essa interação virtual não ocorreu com tanta densidade em uma ferramenta específica de interação virtual, mas foi realizada com intensidade e sucesso pedagógico quando vivenciada como atividade presencial. 
A partir destes resultados considera-se que o Estágio Supervisionado ocupa um lugar privilegiado na formação inicial de professores para a educação infantil. Por meio das vozes destas tutoras, que também são protagonistas da prática pedagógica na educação a distância, foi possível conhecer e compreender algumas possibilidades e limites formativos desse campo de conhecimento, que se constitui o estágio.

\section{Considerações Finais}

O Estágio Supervisionado em Educação Infantil, organizado em forma de disciplina, se apresentou como uma possibilidade formativa para alunos-professores em formação inicial. Identificouse ainda algumas ferramentas assíncronas, que ocorrem como uma forma de comunicação de envio de postagens visíveis por todos os usuários, disponíveis no ambiente virtual Moodle e que foram mais colaborativas em processos de interação, mediação e motivação de aprendizagens destes alunos-professores. Entre estes recursos, as tutoras virtuais reconheceram a importância da ferramenta 'Diário' no Moodle, este último utilizado para a entrega dos Diários Reflexivos de Estágio.

Como ação pedagógica presencial foi destaque o encontro do 'Fórum de Socialização do Estágio' e sua função formativa no processo de compartilhar, dar significados e refletir criticamente sobre as aprendizagens da docência na educação infantil, possibilitadas por meio do Estágio Supervisionado. Todas estas estratégias pedagógicas foram percebidas pelas tutoras virtuais como oportunidades de compartilhamento e reflexão, considerando os materiais estudados $\mathrm{e}$ as experiências vividas em sala de educação infantil.

Destacam-se novas compreensões construídas também pelos alunos-professores sobre suas ideias e crenças relativas às aprendizagens de bebês e crianças, ao processo de educar e cuidar como função da educação infantil, do brincar como eixo de prática pedagógica e não diversão ou passatempo; da importância da intencionalidade nos fazeres docentes e da família como parceira educativa nessa etapa de educação básica. Todos estes aspectos foram ainda destacados pelas tutoras virtuais como (re)aprendizagens adquiridas pelos alunos-professores pela vivência do Estágio no contexto de uma disciplina obrigatória de curso.

Os resultados evidenciaram uma percepção valorosa dos estágios curriculares na formação inicial de professores, afirmando que as inserções participativas em uma escola e sala de educação infantil possibilitam aos estudantes o conhecimento de um campo profissional, a compreensão e análise de um contexto escolar, a aproximação e convivência com o pensar e fazer cotidianos de professores de educação infantil, significando suas experiências.

Considera-se que o Estágio Supervisionado se apresentou ainda como um momento de formação para aluno-professor (re)educar o olhar para um cotidiano pedagógico. Prefere-se a palavra (re)educar justamente pelo fato de que, a maioria desses alunos-professores já possui uma formação inicial em nível superior, em muitos casos uma licenciatura específica, com atuação profissional em outros níveis de educação básica. Por isso, o exercício também mobilizado no Estágio: "Pela via da consciência, pode-se cultivar um olhar sensível, humanizado, compreensível, contextualizado, capaz de romper preconceitos, a partir do compromisso e do exercício da humildade" (OSTETTO, 2011, p. 84).

As tutoras virtuais indicaram ainda a relevância da interlocução dos estudos teóricos realizados no curso e na disciplina com as experiências vividas em campo de estágio, apresentando o Estágio como atividade de relação teoria e prática e assim, distanciando o mesmo de ideias que valorizam a imitação/cópia de práticas docentes ou a aplicação de técnicas ou instrumentais metodológicos, a partir da compreensão de uma docência descontextualizada.

Em relação às limitações da disciplina de Estágio, na formação inicial de professores, os resultados mostraram que o tempo em meses de desenvolvimento da disciplina pode se apresentar como um regulador cronológico das aprendizagens dos alunos-professores e com isso, afetar o processo de estranhamento e conhecimento do novo, no que tange aos contextos escolares de educação infantil e das especificidades da docência nessa etapa educativa.

Ressalta-se a importância da produção de outras pesquisas que possam investigar as implicações do tempo pedagógico das disciplinas desenvolvidas na modalidade de educação a distância, para esse encontro de interações entre o curso de formação inicial e o campo social escola, possibilitado pelo Estágio.

Compreende-se que o lugar ocupado pelo Estágio na formação inicial de professores, segundo a percepção dessas tutoras virtuais, se insere justamente no potencial formativo do mesmo, fertilizando aprendizagens sobre o pensar e os 
fazeres pedagógicos em contextos de docência na educação infantil e que perpassam a construção, muitas vezes, de novas compreensões sobre ser professor de bebês e crianças pequenas.

Os resultados permitem ainda apontar a importância do fortalecimento da participação de tutores virtuais nos processos de planejamento de disciplinas que se desenvolvem na modalidade de educação a distância, em especial os Estágios Supervisionados.

Ressalta-se a importância de produção de outros estudos que possam tornar público o pensamento e os fazeres docentes da tutoria a distância, em cursos de licenciatura que se realizam na modalidade de educação a distância e, que possam contribuir na visibilidade desse modo contemporâneo de fazer a docência.

\section{Notas}

1 Trata-se de um sistema criado pelo Decreto 5800, de 08 de junho de 2006, que integra universidades públicas na oferta de cursos de nível superior, por meio da educação a distância. Outras informações podem ser adquiridas por meio do endereço eletrônico: http://uab.capes.gov.br/

2 Trata-se do tutor a distância, na perspectiva dos Referenciais de Qualidade para a Educação Superior a Distância (BRASIL, 2007).

3 Trata-se de um software livre que tem por objetivo apoiar processos de aprendizagem que ocorrem por meio da internet. Sua sigla significa Modular Object Oriented Distance Learning, mas também é conhecido como Ambiente Virtual de Aprendizagem (http://www.moodlelivre.com.br).

4 A ideia de inserções compreende um convívio com o grupo, de modo a colaborar com aquele cotidiano na qual se insere e 'fazer junto' com as pessoas (crianças, professora, etc).

5 A proposta de participação supera a ideia de estágio como observação neutra de uma realidade. Participar exige envolvimento, apoio, acompanhamento, dispor-se a ajudar, exigindo do aluno-professor disposição e assim buscar conhecer mais profundamente esse cotidiano.

\section{Referências}

BARDIN, L. Análise de Conteúdo. Lisboa: Edições 70, 2009.
BRASIL. Referenciais de Qualidade para a Educação Superior a Distância. Brasília: MEC/SEED, 2007.

- Indicadores de Qualidade na Educação Infantil. Brasília: MEC/SEB, 2009.

. Diretrizes Curriculares Nacionais para a Educação Infantil. Brasília: MEC/SEB, 2010.

BOGDAN, R. C. e BIKLEN, J. Investigação Qualitativa em Educação. Porto: Proto Editora, 1994.

BURNISKE, R. W. Literacia no ciberespaço. Rio de Janeiro: Minion, 2002.

COLL, C.; MONEREO, C. Psicologia da educação virtual: aprender e ensinar com tecnologias da informação e da comunicação. Trad. Naila Freitas. Porto Alegre: Artmed, 2010.

DAL-FORNO, J. P.; CARDOSO, L. C.; RINALDI, R. P. Da construção de uma proposta de estágio na modalidade a distância: a experiência da UFSCar. Olh@res, Guarulhos, v. 1, n1, p. 349-377, maio 2013.

EDWARDS, C.; GANDINI, L.; FORMAN, G. As cem linguagens da criança: a abordagem de Reggio Emilia na educação da primeira infância. Porto Alegre: Artes Médicas, 2010.

FELÍCIO, H. M. S.; OLIVEIRA, R. A. A formação prática de professores no estágio curricular. Educar, Curitiba, n. 32, p. 215-232, 2008.

GOMES, M. Estágios na formação de professores: possibilidades formativas entre ensino, pesquisa e extensão. São Paulo: Loyola, 2011.

GROSSI, M. G. R.; COSTA, J.W.; MOREIRA, M. M. O papel do tutor virtual na educação a distância. Educação, Santa Maria, v. 38, n. 3, p. 659-674, set./dez., 2013.

NEGRINE, A. Instrumentos na coleta de informações na pesquisa qualitativa. In: MINAYO, M.C. S. Pesquisa social: teoria, método e criatividade. $10^{\mathrm{a}}$ Ed. Petrópolis: Vozes, 1998.

OSTETTO, L. E. O estágio curricular no processo de tornar-se professor. In: OSTETTO, L. E. (org.) 
Educação Infantil: saberes e fazeres da formação de professores. Campinas, SP: Papirus, 2008, p 127144.

Deslocamentos, aproximações, encontros: estágio docente na educação infantil. In: GOMES, M. de O. Estágios na formação de professores: possibilidades formativas entre ensino, pesquisa e extensão. São Paulo: Loyola, 2011, p. 79-98.

PERINI, E. Y. P. O Papel do estágio curricular supervisionado na formação inicial de professores: um olhar crítico dos egressos e professores do curso de Pedagogia. 2006. 86 f. Dissertação (Mestrado em Educação - Formação Docente). Universidade do Vale do Itajaí, Itajaí. 2006.

PIMENTA, S.G.; LIMA, M.S.L. Estágio e docência: diferentes concepções. Revista Poiesis, v. 3, n. 3-4, p.5-24, 2005-2006.

Estágio e Docência. $6^{\mathrm{a}}$ ed. São Paulo:

Cortez, 2011.
Souza, A. A. et al. O papel do tutor em cursos a distância baseados em ambientes virtuais de aprendizagem. In: XI Colóquio Internacional sobre Gestão Universitária na América do Sul e II Congresso Internacional IGLU, 2011, Florianópolis. Anais do XI Colóquio Internacional sobre Gestão Universitária na América do Sul e II Congresso Internacional IGLU, 2011. Disponível em:< https://repositorio.ufsc.br/bitstream/handle/1234567 89/26006/3.6.pdf?sequence=1>. Acesso em: 02 de março de 2015.

TARDIF, M. Saberes docentes e formação profissional. $9^{\mathrm{a}}$ ed. Petrópolis: Vozes, 2008.

VYGOTSKY, L. S. Teoria e método em Psicologia. $3^{\mathrm{a}}$ ed. São Paulo: Martins Fontes, 2004.

. A formação social da mente. $7^{\mathrm{a}}$ ed. São

Paulo: Martins Fontes, 2007.

\section{Sobre as autoras}

Aline Sommerhalder: Universidade Federal de São Carlos. Doutora em Educação Escolar e Pedagoga. Docente do Departamento de Teorias e Práticas Pedagógicas/CECH/Universidade Federal de São Carlos; Docente do Programa de Pós-Graduação em Educação/PPGE/UFSCar.

Luana Zanotto: Doutoranda em Educação pela Universidade Federal de São Carlos. Mestre em Educação pela Universidade Federal de São Carlos. Licenciada em Educação Física. Professora do SESC de Araraquara/SP.

Camila Marques dos Santos: Mestre em Educação pela Universidade Federal de São Carlos. Pedagoga. Professora do Senac de Ribeirão Preto/SP.

Recebido em março de 2015.

Aprovado em janeiro de 2016. 